\title{
UPAYA MENGURANGI MISKONSEPSI PADA PEMBELAJARAN FISIKA MELALUI MODEL PEMBELAJARAN INKUIRI (INQUIRY LEARNING)
}

\author{
Ayu Amelia Aprilia ${ }^{*}$, Nana $^{2}$ \\ ${ }^{1}$ Mahasiswa Program Studi Pendidikan Fisika, Universitas Siliwangi \\ ${ }^{2}$ Dosen Program Studi Pendidikan Fisika, Universitas Siliwangi \\ *email korespondensi : aameliaaprilia@gmail.com
}

\begin{abstract}
The purpose of this paper is to describe how the effort to reduce misconceptions in Physics learning material using inquiry learning models. This writing is motivated by the large number of students who are still experiencing errors in understanding Physics learning materials. For this reason, efforts need to be made to reduce misconceptions in learning physics. The inquiry learning model can be used to reduce students' misconceptions. The method used in this paper is the study of literature by studying some literature to be analyzed and made conclusions. The results of this paper show that using inquiry learning models in the physics learning process can be a solution to reduce the misconception of material in the classroom. The inquiry learning model is applied to students where when the activity takes place the teacher is only a guide who directs the students then the students actively seek and understand the learning, generating ideas to find solutions in solving existing problems. Learning can increase student activity in the classroom so that not only accept all the material provided by the teacher but actively seek for themselves and there is openness where learning will facilitate the various hypotheses of students that must be proven and its truth openly.
\end{abstract}

Key Words : Misconception, Inquiry Learning Model, Physics Learning

ABSTRAK : Tujuan penulisan ini untuk mendeskripsikan bagaimana upaya untuk mengurangi miskonsepsi pada materi pembelajaran Fisika menggunakan model pembelajaran inkuiri. Penulisan ini dilatarbelakangi oleh banyaknya peserta didik yang masih mengalami kesalahan dalam pemahaman materi pembelajaran Fisika. Untuk itu perlu ada upaya yang dapat dilakukan untuk mengurangi miskonsepsi pada pembelajaran Fisika. Model pembelajaran inkuiri dapat digunakan untuk mengurangi miskonsepsi pada peserta didik. Metode yang digunakan dalam penulisan ini yaitu dengan studi kepustakaan dengan mengkaji beberapa literatur untuk dianalisis dan dibuat kesimpulan. Hasil penulisan ini menujukkan bahwa dengan menggunakan model pembelajaran inkuiri dalam proses pembelajaran fisika dapat menjadi solusi untuk mengurangi miskonsepsi materi di kelas. Model pembelajaran inkuiri diterapkan kepada peserta didik dimana saat kegiatan berlangsung guru hanya sebagi pembimbing yang mengarahkan peserta didik kemudian peserta didik aktif mencari dan memahami pembelajaran, memunculkan ide-ide untuk mencari solusi dalam memecahkan masalah yang ada. Pembelajaran dapat meningkatkan keaktifan siswa dikelas supaya tidak hanya menerima semua materi yang diberikan guru namun aktif mencari sendiri serta adanya keterbukaan dimana pembelajaran akan memfasilitasi berbagai hipotesis peserta didik yang harus dibuktikan dan kebenarannya secara terbuka.

Kata kunci: Miskonsepsi, Model Pembelajaran Inkuiri, Pembelajaran Fisika 


\section{PENDAhuluan}

Proses yaitu suatu rangkaian atau runtutan perubahan dalam berkembang dan belajar adalah sesuatu yang dilakukan untuk merubah tingkah laku yang biasanya bersifat permanen atau meningkatkan potensi perilaku yang merupakan hasil dari pengalaman. Proses belajar dapat diartikan sebagai salah satu bentuk interaksi antara pendidik dan peserta didik untuk mengubah tingkah laku dan potensi peserta didik ke arah yang lebih positif dalam situasi edukatif. Proses belajar pada peserta didik akan berlangsung secara bertahap dan secara berkala yang diikuti dengan perubahan perilaku peserta didik yang relatif positif sebagai hasil interaksi dengan lingkungan yang tentu melibatkan proses kognitif. Menurut Pinker (dalam Nengah Maharta, 2009: 4), mengemukakan bahwa siswa hadir di kelas umumnya tidak dengan kepala kosong, melainkan mereka telah membawa sejumlah pengalaman-pengalaman atau ide-ide yang dibentuk sebelumnya ketika mereka berinteraksi dengan lingkungannya.

Fisika adalah bagian dari ilmu pengetahuan alam yang membahas mengenai alam yang mempelajari unsur-unsur dasar dalam pembentuk alam semesta, gaya-gaya yang bekerja di dalamnya, dan akibat-akibat yang ditimbulkan mencakup rentang yang luas. Fisika juga merupakan bagian ilmu pengetahuan yang masih ada kaitan dengan mata pelajaran lain seperti biologi dan kimia. Maka Fisika menjadi salah satu mata pelajaran yang sangat penting untuk dipelajari. Menurut Silalahi (Nana \& Pramono, 2019) 60\% dari siswa berpendapat bahwa fisika adalah pelajaran yang sulit dipahami dan kurang dipahami. Hal ini dapat disebabkan karena Proses pembelajaran fisika di sekolah biasanya cenderung berpusat pada guru, sehingga peserta didik lebih cepat bosan pada saat proses pembelajaran berlangsung, karena hal tersebut tidak sesuai dengan gaya belajar yang diharapkan oleh siswa, sehingga belajar menjadi terasa tidak menyenangkan yang membuat siswa menjadi kurang berpengalaman dalam memahami konsep dari materi yang guru berikan dan membuat hasil belajar menjadi rendah.

Berdasarkan data hasil penelitian dari pusat kurikulum (PUSKUR) menurut Karim dan Aviyanti (Nana \& Pramono, 2019), menyatakan bahwa model ceramah dengan guru menulis di papan tulis merupakan model yang paling sering digunakan. Hal ini menyebabkan materi pembelajaran Fisika dianggap sebagai materi hafalan, sehingga siswa tidak memahami konsep yang sebenarnya. Siswa akan mudah merasa jenuh dan bosan dengan metode tersebut sebab tugas siswa hanya mendengarkan yang disampaikan oleh guru saja (Nana \& Pramono, 2019).

Biasanya konsep awal yang telah dimiliki dan diyakini oleh siswa tidak sesuai dengan konsep ilmiah yang sudah disepakati oleh para ahli. Keadaan demikian disebut dengan miskonsepsi. Miskonsepsi tersebut biasanya sulit diatasi karena siswa cenderung mempertahankan konsep awal ini secara kokoh (Ibrahim, 2012). Menurut Sanjaya (2006) mengungkapkan salah satu kelemahan guru dalam mengajar ialah guru tidak berusaha mengajak peserta didik untuk berpikir. Padahal mengajar bukan hanya menyampaikan materi pelajaran melainkan melatih kemampuan peserta didik untuk berpikir. Inkuiri merupakan salah satu model pembelajaran yang menuntut peserta didik harus lebih aktif dalam kegiatan pembelajaran baik dalam hal bertanya dan mengungkapkan pendapatnya serta mengembangkan ide-ide. Pembelajaran dengan model ini berpusat pada peserta didik yang dibimbing oleh guru, peran guru dalam model ini hanya sebagai pembimbing yang mengarahkan peserta didik dalam sebuah pembelajaran di kelas. Model pembelajaran inkuiri dibuat atau dirancang agar mengajak siswa dapat berpikir kritis dan lebih kreatif. Maka dalam hal ini perlunya membahas bagaimana model pembelajaran inkuiri (Inquiry Learning) dapat menjadi solusi dalam mnegurangi miskonsepsi dalam pemahaman materi pembelajaran fisika. 


\section{METODE PENELITIAN}

Metode yang digunakan dalam penulisan ini berupa studi kepustakaan. Data dikumpulkan untuk dianalisis kemudian disajikan dalam hasil dan pembahasan agar dapat dibawa kesimpulan.

\section{HASIL DAN PEMBAHASAN}

\subsection{Miskonsepsi}

Menurut Nana (2018) Ilmu Fisika yang sebagian besar bersifat abstrak dan memerlukan penalaran yang cukup tinggi, sehingga di dalam mempelajarinya menyulitkan siswa dalam menggambarkan ke dalam bentuk yang sebenarnya, dalam memahami konsep-konsepnya serta dapat menjadi verbalisme, hafal kata-katanya tetapi tidak mengerti arti sebenarnya. Ketidakmampuan tersebut telah menyebabkan kesalahpahaman atau miskonsepsi bagi peserta didik dalam mempelajari konsep-konsep mata pelajaran fisika. Miskonsepsi akan sangat menghambat pada proses penerimaan dan asimilasi pengetahuan-pengetahuan baru dalam diri siswa, sehingga akan menghalangi keberhasilan siswa dalam proses belajar lebih lanjut (Klammer, 1998: 7). Paul Suparno (2005) mengungkapkan bahwa untuk mengatasi miskonsepsi ada tiga langkah yang harus dilakukan, yaitu: mencari atau menemukan bentuk-bentuk miskonsepsi, mencari penyebab terjadinya miskonsepsi, dan memilih metode yang sesuai untuk mengatasi miskonsepsi tersebut.

Menurut Van Den Berg dalam (Mosik, dkk, 2010) menjelaskan bahwa miskonsepsi adalah pola berfikir yang kosisten pada suatu situasi atau masalah yang berbeda-beda tetapi pola berfikir itu salah atau dengan kata lain konsepsi siswa bertentangan dengan konsep fisikawan, biasanya menyangkut hubungan antar konsep. Menurut psikologi kognitif, timbulnya miskonsepsi disebabkan adanya asimilasi dan akomodasi pada otak manusia dalam menanggapi dan memahami informasi yang baru diterimanya (Mosik, dkk, 2010). Piaget menyatakan bahwa dengan asimilasi dan akomodasi, informasi baru yang masuk ke otak diubah sampai cocok dengan struktur otak (Van Den Berg, 1991)

\subsection{Model Pembelajaran Inkuiri}

Model pembelajaran Inkuiri merupakan cara pembelajaran yang mengajarkan kepada siswa untuk menjadi kritis, analisis argumentatif dalam mencari jawaban-jawaban berbagai permasalahan yang ada di alam, melalui pengalaman pengalaman dan sumber lainnya. Pada dasarnya inkuiri adalah sautu perluasan proses discovery (penemuan) dalam cara yang lebih dewasa, sebagai tambahan pada proses discovery, Inkuiri mengandung proses-proses mental yang lebih tinggi tingkatannya. Dalam pelaksanaannya model Inquiry itu menghadapkan siswa kepada situasi bertanya-tanya (Gulo, 2008)

Bruner (dalam Suryanti, 2008) menyatakan bahwa model pembelajaran yang menekankan perlunya siswa aktif terlibat dalam proses pembelajaran dan suatu keyakinan bahwa pembelajaran yang sebenarnya akan terjadi melalui penemuan pribadi ialah model pembelajaran inkuiri (inquiry learning). Melalui model pembelajaran inkuiri, peserta didik dapat mengelola konflik kognitif melalui tahaptahap penyelidikan sehingga terbangun konsep ilmiah, yang pada akhirnya dapat mengurangi dan memperbaiki miskonsepsi. Menurut Sanjaya (dalam Setiasih, dkk. 2016) beberapa kelebihan dari model pembelajaran inkuiri yaitu menekan pada pengembangan aspek 
kognitif, afektif dan psikomotor secara seimbang, sehingga pembelajaran lebih bermakna. Memberi ruang kepada siswa untuk belajar sesuai dengan gaya belajar mereka dianggap sebagai model yang sesuai dengan perkembangan psikologis modern, dapat melayani kebutuhan siswa yang memiliki kemampuan rata-rata.

\subsection{Pembelajaran Fisika}

Pembelajaran adalah suatu cara, proses dan perbuatan yang membuat orang ingin belajar. Fisika yaitu ilmu pengetahuan yang memhami tentang fenomena yang ada disekitar dan di alam semesta ini. Peserta didik hanya akan mengerti dengan sungguhsungguh dan mempunyai kompetisi dalam bidang fisika yang digeluti bila peserta didik sendiri aktif belajar, mengolah, mencerna dan merumuskannya dipikirannya sendiri (Paul Suparno, 2013: 1). Menurut Young \& Freedman (2003: 14) fisika ialah suatu cara untuk melihat semesta ini, memahami bagaimana semesta ini bekerja dan bagaimana berbagai bagian didalamnya berkaitan satu sama lain. Pada pembelajaran fisika sudah pasti peserta didik akan berkaitan dengan fenomena yang terjadi di alam dan di kehidupan sehari-hari. Maka dapat dikatakan bahwa pembelajaran fisika yaitu suatu proses membentuk pengetahuan dalam mengkaji dan memahami berbagai macam fenomena fisika yang ada di alam semesta.

\subsection{Upaya Mengurangi Miskonsepsi Pada Pembelajaran Fisika Melalui Model Pembelajaran Inkuiri}

Masalah yang sering muncul dalam proses pembelajaran disekolah yaitu pemahaman materi yang disampaikan guru atau pendidik, penyebab hal ini terjadi salah satunya metode pembelajaran yang sering digunakan dengan metode ceramah dimana siswa hanya dituntu untuk mendengarkan materi yang disampaikan guru tanpa mengajak siswa untuk berpikir aktif dan mengembangkan sikap kritis, sedangkan untuk memahami materi pembelajaran khususnya pembelajaran fisika dibutuhkan konsentrasi yang baik serta siswa yang aktif mencari materi dan mengembangkan sikap kritis untuk selalu menyampaikan berbagai fenomena yang ada, dengan metode yang biasa digunakan siswa cenderung bosan dan mudah beranggapan bahwa fisika itu mata pelajaran yang sulit untuk dipahami dan sering terjadi salah pengertian antara materi pembelajaran dan peserta didik yang menanggapinya.

Menurut Yu Je Lee (Nana, 2018) secara garis besar penggunaan model juga harus fleksibel karena didasarkan pada situasi dan kondisi di sekolah dengan tujuan untuk merangsang daya kreatif siswa. Model pembelajaran inkuiri memiliki beberapa kunggulan yaitu dapat membantu peserta didik dalam menggunakan ingatan yang sudah ada untuk dikaitkan dengan konsep yang akan dibahas, mendorong siswa untuk berpikir dan bekerja atas inisiatifnya sendiri, memberi kebebasan pada siswa untuk dapat berpikir dan memecahkan masalah atas masalah yang sedang dihadapi (Roestiyah, 2012).

Menurut Nana (2019) dan Pramono (2019) model pembelajaran inkuiri ini cocok diterapkan dalam pembelajaran Fisika, hal ini dikarenakan Model inkuiri lebih menekankan pada keaktifan siswa dalam belajar, siswa terlebih dahulu mengadakan kegiatan-kegiatan di laboratorium atau disekitar yaitu proses mengamati, mencatat hasil pengamatan, menganalisis dan menyimpulkan kegiatan praktikum yang dirancang oleh guru, maka hal itu akan membuat belajar Fisika menjadi lebih menyenangkan dan lebih berkesan. Karena, siswa terlibat langsung dalam proses pembelajaran, Fisika merupakan mata pelajaran yang bukan menuntut hafalan namun perlu dimengerti, dipahami dan diterapkan (Nana \& Pramono, 2019). Dilihat dari banyaknya 
keunggulan yang ada pada model pembelajaran inkuiri, maka model ini dapat dijadikan solusi dalam upaya mengurangi miskonsepsi peserta didik pada pembelajaran fisika serta guru harus lebih kreatif dalam mencari masalah untuk dipecahkan oleh peserta didik.

\section{PENUTUP}

Dari berbagai pembahasan yang telah dijabarkan dapat ditarik kesimpulan dan dimaknai bahwa upaya mengurangi miskonsepsi dalam pembelajaran khusunya pada pembelajaran fisika bisa di kurangi dengan model pembelajaran inkuiri (Inquiry Learning). Peserta didik akan berperan lebih banyak dalam kegiatan pembelajar dengan cara belajar yang mengedepankan peserta didiknya untuk berpikir aktif, kreatif dan dapat mencari solusi dalam menyelesaikan masalah yang ada sehingga siswa akan lebih termotivasi dan lebih semangat dalam mempelajari materi pembelajaran fisika, serta peran guru sebagai pembimbing dan mencari suatu perasalahan untuk dipecahkan oleh peserta didik.

\section{UCAPAN TERIMA KASIH}

Terima kasih kepada semua pihak yang telah membantu demi kesempurnaan artikel ini menjadi lebih baik. Terima kasih juga saya ucapkan kepada Dr. Nana, M.Pd. yang telah membimbing dalam penyusunan artikel ini.

\section{DAFTAR PUSTAKA}

Fajar, D. M \& Z. A. Iman Supardi. (2013). Pengaruh Penggunaan Model Pembelajaran Inkuiri (Inquiry Learning) Terhadap Penurunan Miskonsepsi Pada Materi Listrik Dinamis Kelas X Sman 2 Jombang. Jurnal Inovasi Pendidikan Fisika. Vol 2 (2). 24 - 29.

Gulo, W. (2008). Strategi Belajar Mengajar. Jakarta: Grasindo Hamdani.

Ibrahim, Muslimin. (2012). Konsep, Miskonsepsi, dan Cara Pembelajarannya. Surabaya: UNESA University Press.

Klammer, J. (1998). An Overview of Techniques for Identifying, Acknowledging and Overcoming Alternate Conceptions in Physics Education. 1997/98 Klingenstein Project Report, Teachers College Columbia University.

Maharta, Nengah. (2009). Analisis Miskonsepsi Fisika Siswa Sma Di Bandar Lampung. Bandar Lampung: Universitas Lampung.

Mosik, Maulana, P. (2010). Usaha Mengurangi Terjadinya Miskonsepsi Fisika Melalui Pembelajaran Dengan Pendekatan Konflik Kognitif. Jurnal Pendidikan Fisika Indonesia. Vol 6 (2). 98-103.

Nana, N. (2019). PENERAPAN MODEL CREATIVE PROBLEM SOLVING BERBASIS BLOG SEBAGAI INOVASI PEMBELAJARAN DI SEKOLAH MENENGAH ATAS DALAM PEMBELAJARAN FISIKA. Prosiding SNFA (Seminar Nasional Fisika dan Aplikasinya), 3, 190-195. doi:http://dx.doi.org/10.20961/prosidingsnfa.v3i0.28544

Nana, N. (2018). Penggunaan Pendekatan Konflik Kognitif Untuk Remediasi Miskonsepsi Pembelajaran Suhu dan Kalor. Prosiding Seminar Nasional Pendidikan Sains, 8- 14. 
Nana. (2019). Upaya Peningkatan Kemampuan Kognitif dan Komunikasi Ilmiah Siswa Kelas X MIA 1 SMA Negeri 1 Ciamis Menggunakan Model Pembelajaran Inquiry. Difraction. Vol 1 (1). 1-10.

Roestiyah. (2012). Strategi Belajar Mengajar. Jakarta: Rineka Cipta Sanjaya,

Wina. (2006). Pembelajaran dalam Implementasi Kurikulum Berbasis Komputer . Jakarta: Kencana.

Setiasih, dkk. (2016). Penggunaan Model Inkuiri Untuk Meningkatkan Hasil Belajar Siswa Pada Materi Sifat-Sifat Magnet Di Keas V SDN Sukajaya Kecamatan Jatinunggal Kabupaten Sumedang. Jurnal Pena Ilmiah. Vol 1 (1). 421-430.

Suparno, Paul. (2005). Miskonsepsi \& Perubahan Konsep Dalam Pendidikan Fisika. Jakarta: Grasindo.

Suparno, Paul. (2013). Metodologi Pembelajaran Fisika: Konstruktivisme dan Menyenangkan. Yogyakarta: Universitas Sanata Dharma.

Suryanti, dkk. (2008). Model-model Pembelajaran Inovatif. Surabaya: Unesa University Press.

Van Den Berg, Euwe. (1991). Miskonsepsi Fisika dan Remediasi. Salatiga: Universitas Kristen Satya Wacana

Young, Hugh D. \& Roger A. Freedman. (2003). Fisika Universitas. Jakarta: Erlangga. 